Revista da ANPOIL, n" 5, p. 183-193, jul./de\%., 1998

\title{
JACQUES ROUBAUD: A POESIA COMO ESPIRAL DA MEMÓRIA
}

\author{
Paula Clenadel l,eal*
}

\begin{abstract}
RESUMO: Jacques Roulxud mantém uma permanente reflexão sobre o lempos e a memória em selus textos. Ein Quelyue chose noir; soma-se a essa reflezōoo o penssamento poélico da ausência. A memória, luz e sombru, conduzo o percurso da

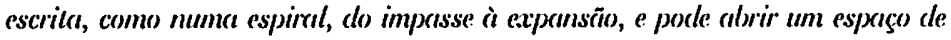
intensidecle parre a produçūo) poélicu contemporrûnett.
\end{abstract}

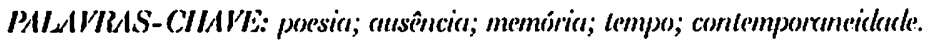

Mómoire de la poésie: lumière noire de la mémoire: diaphane de l'olssar; en nous.'

(1) pocta francês Jacques Roubaud, cm scu livro Quelque chose noir, dedica-sc a claborar a perda de Alix Cléo Roubaud, assim como a posição que cle ocupa cm relação a cssa pcrda. Primciro texto escrito pelo pocta após trinta meses de silêncio obstinado posteriores à morte da mulher; o livro tem a dupla marca da morte $\mathrm{c}$ da ressurrcição (da pocsia). Como organizar; por mcio da linguagem poćtica, a perda? Como não dcixar de acreditar na possibilidade da poesia frente à aparente dissolução da memória, ainda mais çuando a situação da pocsia, a "arte da memória" por cxcclência, scgundo Roubaud, parcce cada vez mais precária no mundo contemporânco? Estas são as grandes questões que atravessam o livio de Roubaud.

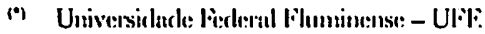

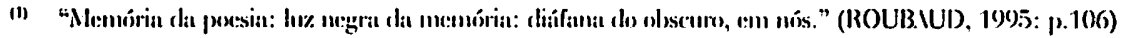




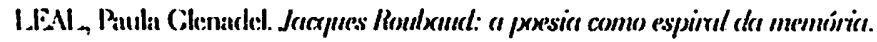

A perda, cm Roubaud, ecoa em diversos níveis: primeiramente, como perda do corpo amado, diluição, dissolução, intcrrupção de uma vida cm comum, dc uma relação com o cspaço habitado cm comum. Aqui, a concretude da perda abre-sc para uma contemplação do espaço c da paisagem, que passam a significar, a falar da ausência da mulher; revestidos de imagens particulares, de blocos de memória. Thata-se de um tipo de memória "curta", assim chamada por Dclcuzc c Cuattari cm contraste com a î́remória "longa" das grandes tradiçōes, da família, da raça, da sociedade ou da civilização c que, diferentemente destas, “(...) compreende o esquecimcnto como processo"(DEIJUUZE c CUA'T'ARI, 1980: p.25), raño pela qual cla se torna particularmente interessante para a arte.

A memória "curta", scgundo cssa abordagem, pode gerar um modo particular de individuação, uma hecceidade" ${ }^{2}$, um agenciamento entre um lugar c um tempo, uma hora, uma paisagem, uma estaçã̄o do ano, um personagem, somados a velocidades c afctos, ligados de modo indissociável, configurando uma individualidade autônoma, "que não se confunde com a de um objeto ou de um sujcito" (DEL_LUZLE e CUA'T'IARI, 1980: p.318). Assim ocorre na poesia de Roubaud que, em lugar de procurar fixar lembranças como objetos privilegiados de memória, se deixa invadir e se torna o lugar em que memória c csquecimento se entrclaçam.

Aqqui, como no conto de Cícero sobre Simônides de C'eos que o poeta comenta cm L'invention du fils de Leoprepes, a menória aparece como ao mesmo tempo mortal c divina, à scmelhança dos dióscuros Cástor c Pólux - inscparávcis, mas de naturczas diversas: cla ć, assim, "constelação fulgurante da lembrança c sombra empocirada do esquecimento" (ROUBAUI), 1993: p.12). O duplo cstatuto da memória permite atribuir à arte $\mathrm{cm}$ geral c à pocsia em particular o dom de arrancar; ao menos por algum tempo, a memória a sua dissolução incvitável.

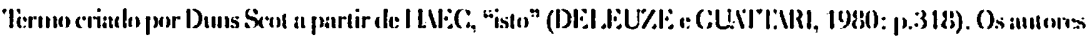

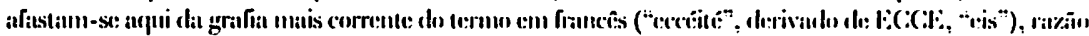

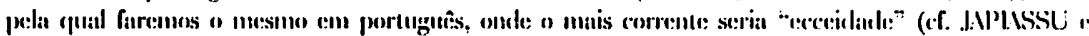

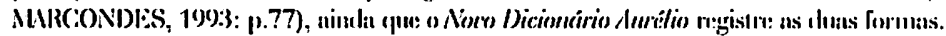


Revista da INIOO/d, n" 5, p. 183:3-193, jul./deะ.., 1998

O acontecimento da pocsia de Roubaud é, portanto, da ordem da constituição de hecceidades, ou blocos de memória, como o "golfo de tethados à esquerda da igreja", que retorna freqüentemente, com diferentes valores a cada vcz (ROUBAUD), 1986: p.31, 37, 91). lisses blocos são provenientes de diferentes momentos da claboração da perda, que se sucedem c se chocam uns contra os outros. É o que se lê cm "Dans l'espace minime" ("No espaço mínimo"), pocma que integra o livro:

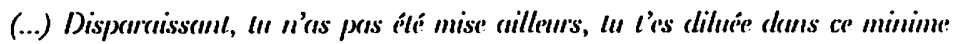

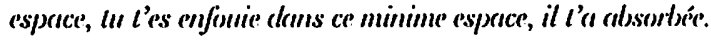

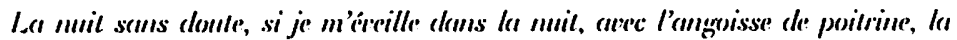

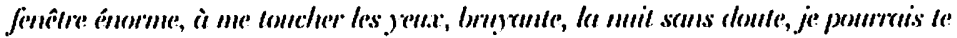

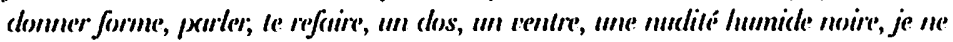
m'y chloundonne pors.

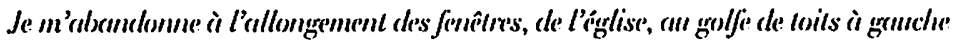

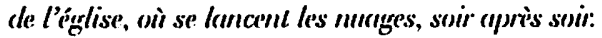

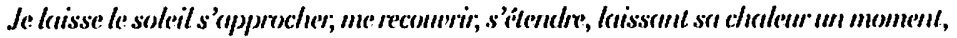

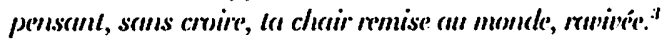

O movimento de Quelque choise noir é, de alguma forma, o de uma espiral: o circuito da memória e do esquecimento fornece a primcira volta, mas não dá resolução à questão da ausência da mulher; levando a um ponto de impassc ou de inflexão, ponto onde todo o rigor da claboração da perda se cxcrce, o "ponto vacilante" - título de um poema do livro, cm que Roubaud fala do "ponto familiar da dúvida de tudo"(ROUBAUD, 1986: p.20).

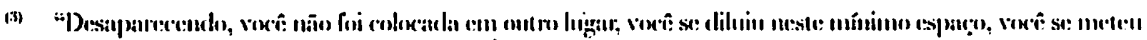

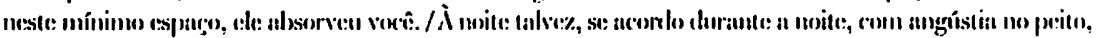

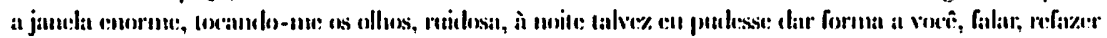

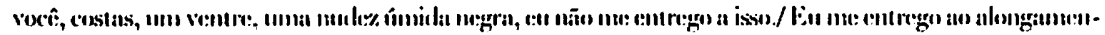

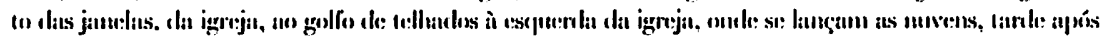

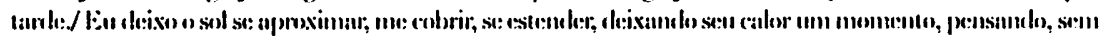

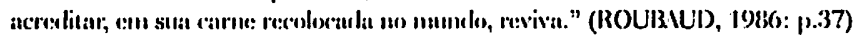


IEAL, Paula Clenadel. Jacques Roudsaud: a poesia como espirral da memoiria.

Isto torna-sc evidente quando cle traça um scgundo círculo $\mathrm{cm}$ seu projeto, imaginando uma realidade organizada a partir de uma outra lógica, como nos versos seguintes, do pocma "Roman-photo"("Fotonovela", expressão que é tcstemunha do rigor crítico com que o pocta vê sua tentativa, além de cvocar a condição de fotógrafa de $\Lambda$ lix Cléo): "I_c roman se passe dans plusicurs mondes possibles. Dans certains, la jeune femme n'cst pas mortc."

Ou ainda no pocma "Univers"("Univcrso"), em que se propōe a idćia scgundo a qual a ausente deste universo cstaria presente cm outro, dotado de uma lógica simétrica mas inversa:

"Elle est vicumle". j'imagine que celle propossition, fausse denns mon umiucrs, est vrrie ckuns cel cuture, l'univers (ficti) de sa vórité.

\section{(...) L'univers resle insensible à l'olfie de ma proposilion!.}

Dans l'uniers de celle parrole, n'existe pas "elle serriit vivante", el pas pless "il

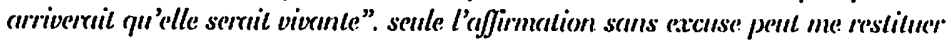
un instant, comme ume résine, le pouffum de la nudité.

La proposition "Iu es' morte", elle, n'a besoin d'aucun univers de discours.

Elle ne restitue aucun sens: ni la mue, mi les aumes. (...)"

Assim, o impassc instala-sc novamente, pois a proposição "cla está viva" perde sua validade no universo de discur'so $\mathrm{cm}$ que o poeta tem de mover-sc, $\mathbf{c}$ cncontra como limitc a impossibilidade de atingir sua cxistência concreta. Ocorre cntão a desestabilização da proposição-proposta

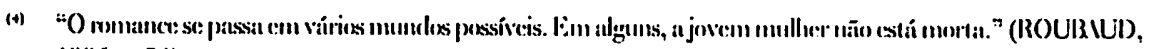
1986: 1.51$)$

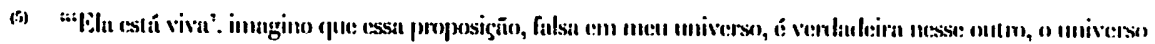

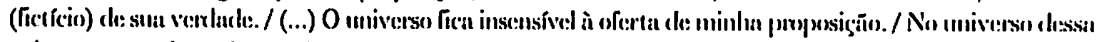

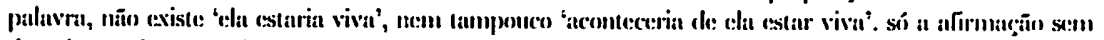

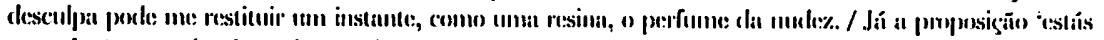

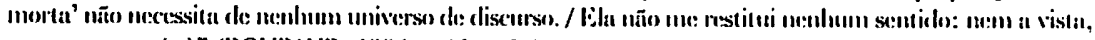

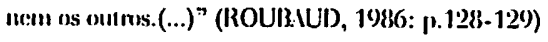


lançada pelo pocta, "ponto vacilante"que irá marcar a partida para novo círculo na espiral.

O movimento prolonga-se numa outra dimensão da perda, que aparcec também como quebra da referência pacilicadora no contato com as coisas. Ela implica a perda da consistência significante do sujeito, uma vez rompido o agenciamento instaurado com a mulher: $O$ poema "Une logicue" ("Uma lógica") coloca $\mathrm{cm}$ evidência a naturcza desse agenciamento: um biipsismo, um modo de estar no mundo que consiste em estar "isolado a dois", um equilíbrio entre diferentes. O uso dlos verbos no condicional nesse poema indica o carráter vagamente utópico da organização - que não passa despercebido a Roubaud, como se vê cm "utopiquement unics", "lî̀le du deux", cm que a ilha ć uma imagem privilegiada da utopia -, mas cxprime, principalmente, a distância imprimida pelo pensamento retrospectivo, uma vez que o sujeito que fala no pocma apresenta essa "lógica" como seu ideal perdido. A necessidarde em que a consciência brutalmente devolvida ao solipsismo se encontra de reaprender a perceber o mundo configura um novo impasse, uma nova volta da espiral.

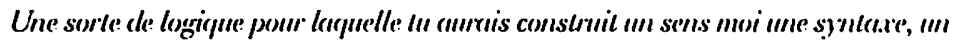
morlile, des crilculs

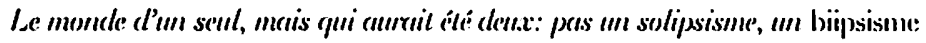

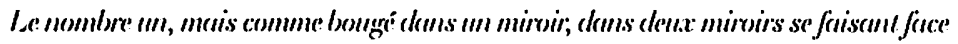

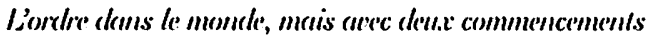

Dị]ierrmls, insépourubless

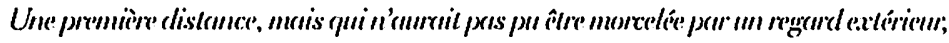
une messure de colle distance, mais qui n'aumruit pas pu être prise sans fanssser le systime du double: inn caxiome d'incertilude.

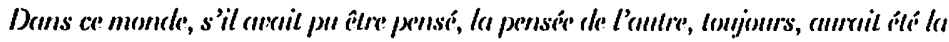
pensín de "l'cuntre de dence." 


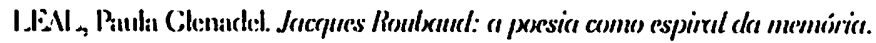

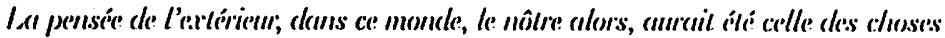

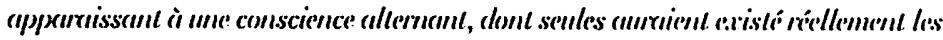

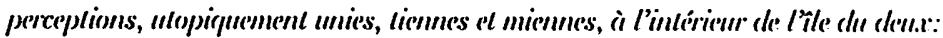

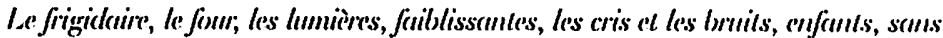

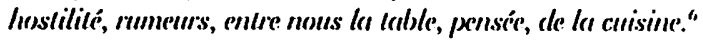

A imagem da espiral, em que pese a conotação "infernal" ("On y descend par une spirale, une damnation." ") que cla pode adquirir; devido ao contínuo e desconfortável deslizamento que imprime às posiçōes de um sujcito da enunciação que buscasse um patamar de estabilidade, é extremamente produtiva no texto de Roubaud. Ela movimenta um paradoxo: uma vez no caminho da assimilaçăo, a perda irá mover uma indlagação acerca da oscilação entre ausência e presença que será a base da produçāo poética. É a passagem por cada volta dessa espiral, suscitada pela impossibilidade de se manter o mesmo movimento além do ponto de impasse, que produz a escrita.

Tomar a palavra, firente à impotência da linguagem em evocar concretamente a presenģa de Alix Cléo c a sua simultânéa clicácia em relimitar os contornos da ausência, acaba por implicar um traballıo sutil de comunicaçãa entre esses dois bordos. As idas e vindas dos textos que compõem o livro - alguns se enunciam desde a perspectiva (imaginária) da presença, outros desde a perspectiva da ausência (igualmente imagginária, uma vez quic dotada de um poder evocatório que já é, diferenciando o

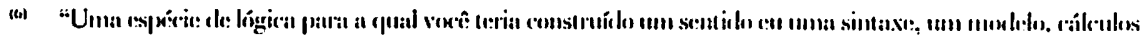

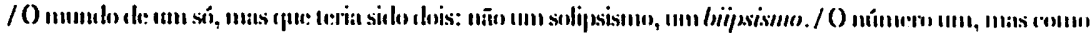

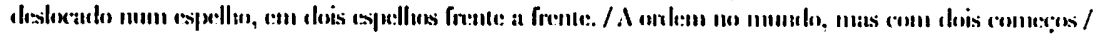

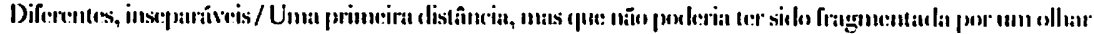

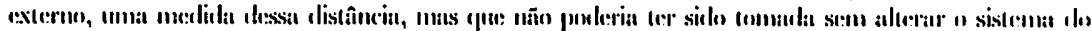

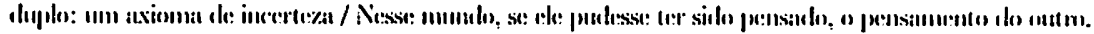

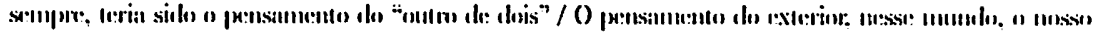

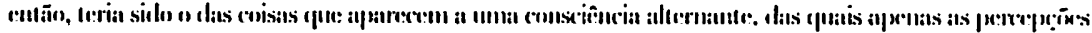

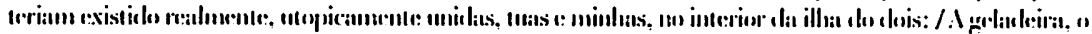

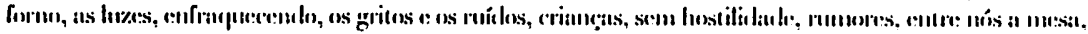

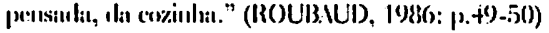

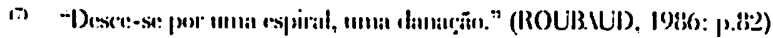




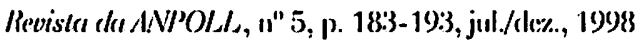

nada, o indiferenciado) - criam uma rede complexa de linhas, uma composiçāo ao mesmo tempo "lítmica e pictural".

A ausência/presença aparece, assim, como o tema do livıo de Roubaud, constituindo, ao mesmo tempo, o motivo c a cstrutura reguladora da cocsão e da dispersão de scus elementos, como o sugere, entre outros, o poema "Méditation de la comparaison"("Meditação da comparação"):

(...) Je m'scherne ì circonscrire rien-toi ruve excoctitucte, ce bipôle impossible, ì

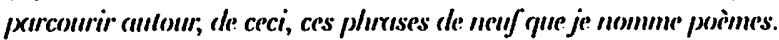

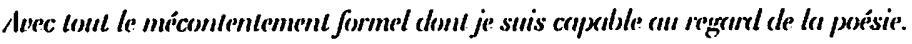

Linure les mois de silence oñ je ne me problongereis que murt.

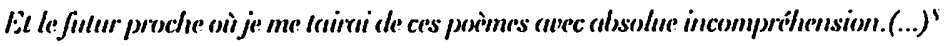

Aquii, a reflexão sobre o lugar do poético encontra um lugar privilcgiado. Para Roubaud, a poesia é antes de mais nada o lugar da memória, lugar tanto das hecceidades ou blocos de memória, quanto da memória das possibilidades e impossibilidades da língua, relletidas na memória da própria poesia. Marcando alguns momentos do percurso de Roubaud, encontramos a memória da poesia, por exemplo, nas ressonâncias de Dante, sob forma da "espiral da danação", lembrança dos círculos concêntricos infernais, c também da construção da poesia como busca da mulher; que atua no sentido de promover a harmonização do universo do pocta. De Mallarmé, é retomada a sutil meditação sobre a ausência de Nlix Cléo, "Endormic de son absence absolue évcillée dans son absence intermittente"), herança de "l'absente de tous bouquets"

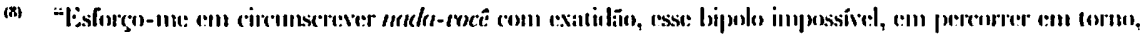

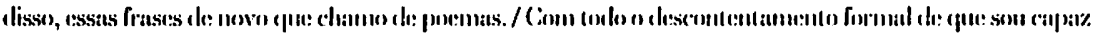

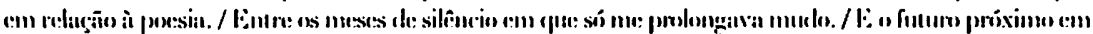

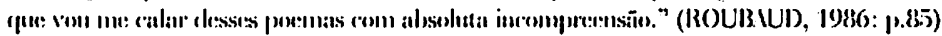

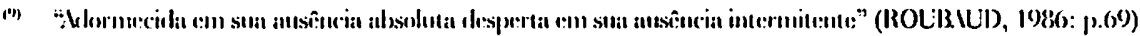

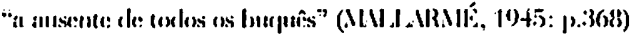




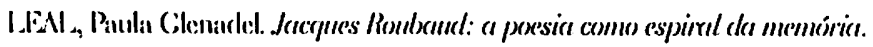

Sc as hecceidades constituem o recurso formal primordial de sua pocsia, a conviç̧ão de que a pocsia torna possível o impossível da língua é o fôlego que anima a invenção formal. Roubaud, reatando a liliação mallarmeana de sua poesia, alirma:

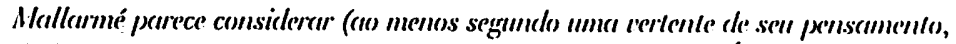
"otimista") a poessia como instrumento perfeito de lingure. É por isso que ela

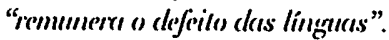

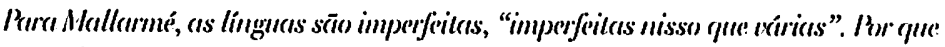

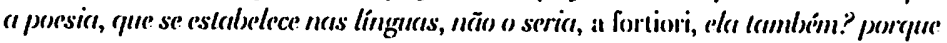

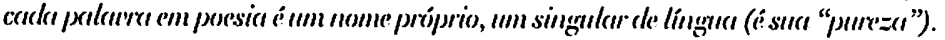

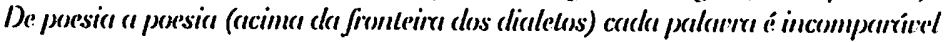

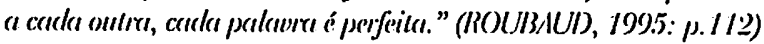

No pocma "Apatride"("Apátrida"), dentro de Quelque chose noir, Roubaud propõc um cspaço paradoxal em que as distinções entre anterioridade c posterioridade se esvaziam, criando uma espécie de "presente" contínuo que possui as propriedades da memória. Obtém-sc, assim, dentro do poema, o processo e o resultado do processo ao mesmo tempo, o impulso criador c scu simultânco reflexo na obra, numa representação da cena fulgurante da Idćia mallarmeana:

Te nommer c'est faire briller la présence d'un ôtre cuntérienur à la disperuitiont.

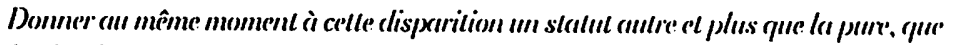
la simple absence, an stalut second"

Ėsse "cstatuto scgundo" da ausência, já mediado pelo fazer do pocta, corresponde ao papel que Roubaud atribui à poesia, que é o de ser; principalmente, um catalisador de memória, capaz de agir sobre a singularidade de carla leitor; considerado enquanto lugar de uma memória especílica que não é compartilhada com os demais, além daquela que cle

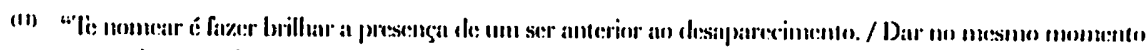

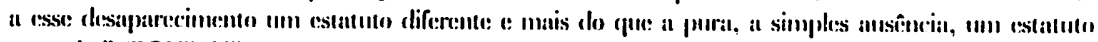
se:gunto." (ROUI3.IUD, 1986: p.87) 


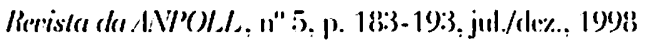

compartilha culturalmente com o tempo e o espaço de sua cxistência. () efeito de memória criado pela poesia conduz o processo de constituicaño de um sujeito em sua língual:

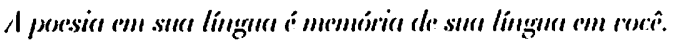

- Comm?

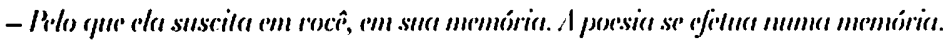

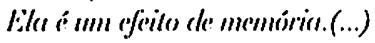

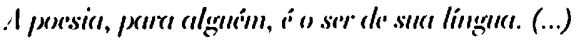

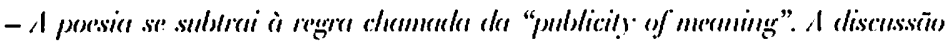

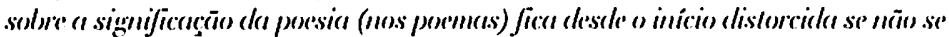

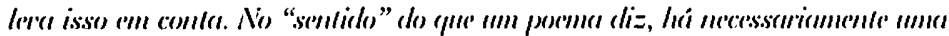

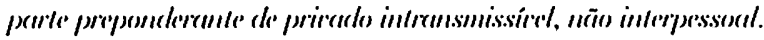

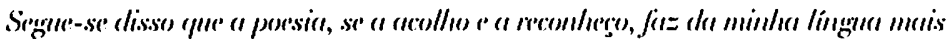

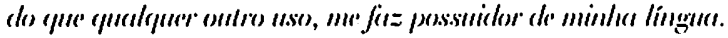

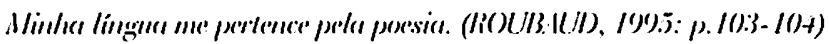

Contudo, a possibilidade da poesia como processo desenciadeador da memória, aguindo no espaço do privado intransmissível, hoje, torna-se menos evidente, dentro do quadro daquilo que Deleuze e Foucault, de manciras complementares, apontaram como uma passagem, realizada cm diferentes níveis segundo a parte do mundo (que escolhermos observar; mas em vias de fianca ghobalização, de uma sociedarle que pune a uma sociedade que vigia: a instalagão de ame sociedede de conlrole ${ }^{12}$. Os produtos discursivos da sociedade contemporânea refletem e reforģam, num movimento de dupla prorlugão, os paunametros desse controle, exercirlo, entre outras formas, pelo esvaziamento, massificação e deglutição das diferenças numa espécic de "consenso" morno.

Esse contexto cria um impasse para a poesia tal como Roubaud a entende, e desemboca numa incompatibilidade, numa falta de sincronicidade, entre vários elementos do processo, a saber: o poeta, os leitores de

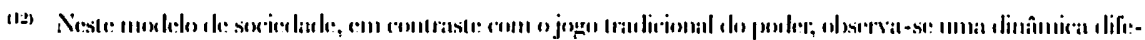

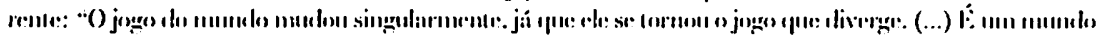

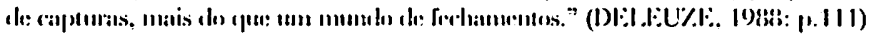




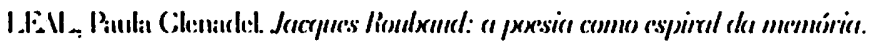

pocsia c a tradição poética (inclusive a tradição vanguardista de ruptura). A saída para o impasse, propõe Roubaud, consistiria em medir a dificuldade da poesia pela dificuldade do tempo em que vivemos, apreendendo-a como sintoma não da fácência da própria poesia, mas da unilormização do pensamento que ocorre paralelamente à perda dos espaços de questionamento individual. É o que descreve uma teórica contemporânca, confatizando a necessidade da "revolta", entendida como resistência, como reconstituição de um espaço íntimo:

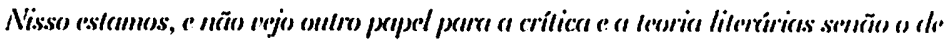

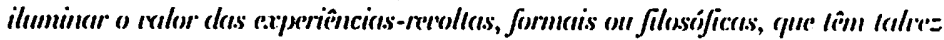

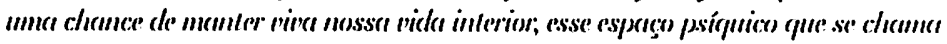

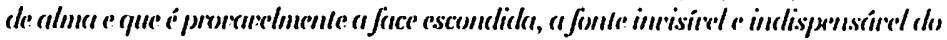
Brlo. (KTISTIY:1', 1996: p.22)

Partindo dessa constatação, que segue a mesma direção do diagrnóstico feito por Roubaud dos impasses de nossa ćpoca, cabe à cxperiência da poesia, para continuar a ser possível hoje, assumir um caraíter de resistência individual, de enfientamento da própria recusa da poesia, combartendo o que o poeta chama de "preguiçoso abandono aos modos de existência contemporâncos" (ROUBAUI), 1995: p.2?'4-275).

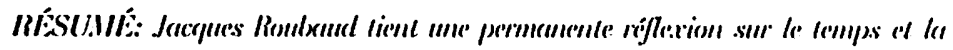

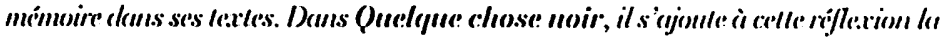

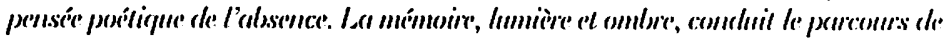

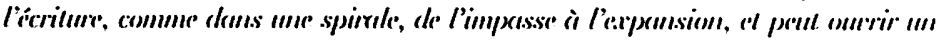

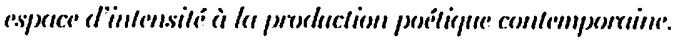

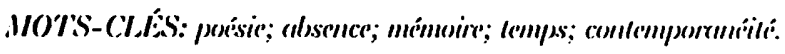

\section{BIBLIOGRAFIA}

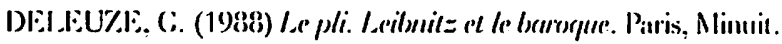




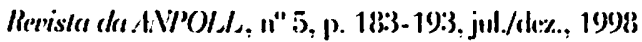

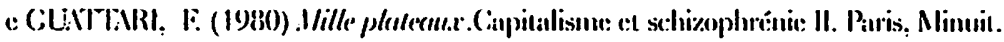

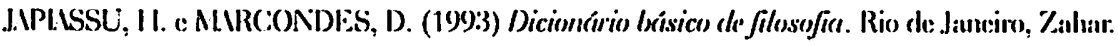

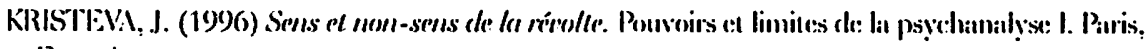
fingurt.

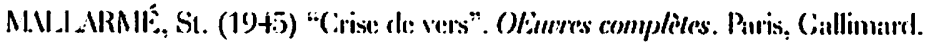

ROUl3.UUD, J. (1986) ()melque chose moir. Pilris, (;illimarrl.

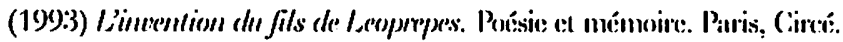

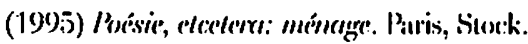

